\title{
Os precatórios e as finanças públicas brasileiras
}

André Luiz Fernandes*

Adriana Sbicca*

RESUMO - Este artigo apresenta uma análise sobre o problema da inadimplência em face da dívida pública resultante dos precatórios, motivação principal de uma profusão de alterações constitucionais.

Palavras-chave: Precatórios. Finanças públicas. Inadimplência.

\section{INTRODUÇÃO}

Os bens públicos são impenhoráveis e, deste modo, não podem ser utilizados para responder pelas dívidas do Estado. Assim, quando o Estado é condenado a indenizar o particular, surge o precatório. Precatório é o termo que designa a requisição feita pelo Poder Judiciário ao Poder Executivo para que efetue o pagamento de uma determinada quantia em dinheiro referente à indenização acima referida. O precatório representa, então, um direito de receber um montante em dinheiro do Estado mas que está, pela Constituição Federal, submetido a algumas condições, dentre as quais, a de que cada pagamento só pode ser efetuado se for respeitada a ordem cronológica de apresentação (de forma a não privilegiar algum credor em detrimento dos demais) e, além disso, o valor a ser pago deve estar contemplado no orçamento anual do ente público para possibilitar o planejamento e o controle dos gastos públicos.

Os precatórios são disciplinados no artigo 100 da Constituição Federal, que determina a obrigatoriedade de inclusão, no orçamento das entidades de direito público, da verba necessária "ao pagamento de seus débitos, oriundos de sentenças transitadas em julgado, constantes de precatórios judiciários apresentados até $1^{\circ}$ de julho, fazendo-se o pagamento até o final do exercício seguinte, quando terão seus valores atualizados monetariamente" ( $\left(5^{\circ}\right.$ do art. 100 da Constituição Federal). Desta disposição resulta que o prazo normal para o credor ter acesso aos recursos a ele devidos não ultrapassará dezoito meses e que seus valores serão corrigidos monetariamente.

O problema surge quando o Estado não paga e a Constituição Federal de 1988 já

\footnotetext{
* Mestre em Desenvolvimento Econômico pela Universidade Federal do Paraná. Bacharelando em Direito pela Universidade Federal do Paraná. É analista de controle do Tribunal de Contas do Estado do Paraná. Endereço eletrônico: aluiz@tce.pr.gov.br.

** Doutora em Economia de Empresas pela Escola de Economia de São Paulo - Fundação Getúlio Vargas. É professora do Departamento de Economia da Universidade Federal do Paraná. Endereço eletrônico: adsbicca@ ufpr.br.
} 
foi emendada quatro vezes em função do que parecem ser tentativas de solucioná-lo. O sistema teve seus contornos bastante modificados pelas alterações constitucionais mais recentes e, dentre estas, destacam-se a exclusão de valores a receber de menor monta, que se tornaram as “obrigações de pequeno valor" e passaram a ser pagas no mesmo exercício da requisição e a subdivisão dos precatórios em alimentares ${ }^{1}$ e não alimentares, ou comuns.

Todavia, com um endividamento crescente, resultante de diversos fatores que impedem o adimplemento da dívida de precatórios e com a sensibilização do STF em face da penúria imposta aos credores insatisfeitos ${ }^{2}$ surgiu, em dezembro de 2009, a Emenda Constitucional 62, que trouxe mudanças radicais ao sistema. Das alterações mais importantes, pode-se destacar a obrigação dos entes inadimplentes de depositarem em conta corrente especial um percentual fixo da sua receita corrente líquida (RCL) para saldar a dívida e a transformação do Tribunal de Justiça de cada estado em administrador desta conta, a qual passa a centralizar todos os pagamentos de cada um dos devedores em face dos precatórios emitidos por todos tribunais. Também foram criadas novas formas de efetuar o pagamento, não mais atreladas à ordem cronológica de apresentação. Dentre essas, o leilão reverso, no qual o credor que der maior desconto na dívida que o ente federado tem para com ele, recebe antes.

A questão é complexa e de grande repercussão social e a controvérsia sobre o assunto é grande. Para o desembargador Ivan Sartori (SARTORI, 2010), a partir da análise da experiência vivida pelo estado de São Paulo em relação aos precatórios, a questão está relacionada a problemas insolúveis como falta de planejamento dos governos e falência completa do sistema. Já Moreira (2010), chamou a atenção para a questão financeira, destacando que as Emendas propostas são tentativas de resolver um velho problema, um sintoma de patologia das finanças públicas: os recursos públicos são um bem escasso e as despesas são crescentes. Há um descompasso na capacidade de adimplemento do Estado e o problema que se coloca não é patrimonial mas, sim, de liquidez.

O desafio da inadimplência e o grande peso dos argumentos do âmbito financeiro utilizados na discussão, tornam necessária a análise de algumas questões que tocam a problemática da inadimplência sob a ótica das finanças públicas, tema deste artigo.

$1 \mathrm{O}$ art. 100 da Constituição Federal, em seu $\int 1^{\circ}$ - A, traz a definição dos débitos de natureza alimentícia: "Os débitos de natureza alimentícia compreendem aqueles decorrentes de salários, vencimentos, proventos, pensões e suas complementações, benefícios previdenciários e indenizações por morte ou invalidez, fundadas na responsabilidade civil, em virtude de sentença transitada em julgado".

2 A situação para o cidadão é a seguinte: após passar pelo tortuoso caminho da obtenção de uma decisão favorável contra o Estado, transitada em julgado, ele ainda se vê obrigado a esperar pelo recebimento dos precatórios. No caso do estado do Paraná, esta espera já significou oito anos na fila dos precatórios, se alimentares, ou doze anos no caso dos precatórios comuns ou não alimentares (TCE-PR, 2010, p. 3). 


\section{A INADIMPLÊNCIA}

Há grande desencontro de informações sobre a dívida pública de precatórios dos estados e dos municípios brasileiros. Este trabalho usa duas fontes de informação para permitir uma melhor avaliação da dívida nos três níveis de governo: a base da Justiça Federal, que contém as séries históricas de pagamentos de precatórios e de requisições (ou obrigações) de pequeno valor efetuados pelo Governo Federal e, para o estoque da dívida com precatórios e pagamentos efetuados pelos municípios e pelos estados, foi utilizada a base de dados do Tesouro Nacional.

De acordo com a Justiça Federal, o Governo Federal se encontra adimplente com relação aos débitos judiciais, tendo efetuado o pagamento, no ano de 2010, de 8,1 bilhões de reais em precatórios e de 4,5 bilhões de reais em requisições de pequeno valor, somando pouco mais de 12,6 bilhões de reais. A título de comparação, este valor representa quase metade da dotação original do Plano de Aceleração do Crescimento (PAC) daquele ano ${ }^{3}$. Com esta magnitude de despesa, pode-se afirmar que os pagamentos efetuados pelo Governo Federal a título de precatórios e de requisições de pequeno valor têm potencial para gerar efeitos nada desprezíveis na economia do país.

Os valores pagos por beneficiário e por processo são as grandezas que apresentam uma tendência de relativa estabilidade, tanto na despesa com precatórios quanto nas requisições de pequeno valor. Já as quantidades de beneficiários e de processos, seja de precatórios ou de requisições de pequeno valor, apresentam tendência crescente. Apesar do crescimento dos pagamentos entre os anos de 2009 e 2010 se tornar menos acentuado, nada indica ainda que haverá estabilização destas duas variáveis. Esta tendência de crescimento dos pagamentos de precatórios e de requisições de pequeno valor se apresenta mesmo quando efetuada a correção monetária dos anos anteriores a 2010, de forma a ser descontado o efeito inflacionário.

O estoque da dívida de precatórios dos municípios totalizava quase 21 bilhões de reais em 2010. O percentual de municípios inadimplentes variou, de 2007 e 2010, entre 11\% e 15\% do total de municípios da base de dados (que abarca a quase totalidade dos municípios brasileiros). Da Tabela 1, percebe-se uma tendência de crescimento, tanto na quantidade de municípios inadimplentes, quanto no estoque de dívida e no somatório de pagamentos de precatórios. Embora tenha ocorrido um aumento do volume de pagamentos de precatórios entre 2009 e 2010, este aumento não se mostrou suficiente para evitar que crescesse, de forma mais do que proporcional, o estoque da dívida da totalidade dos municípios.

3 De acordo com o Relatório 2007-2010 do PAC, para 2010, o investimento previsto foi de 25 bilhões de reais. Documento disponível em: <http://www.brasil.gov.br/pac/relatorios/nacionais/11o-balanco-4-anos/parte-1/ view>. Acesso em 25/8/2011. 
TABELA 1 - DÉBITOS JUDICIAIS DOS MUNICÍPIOS - BRASIL (VALORES CORRENTES)

\begin{tabular}{lrrr|r|r}
\hline \multicolumn{1}{c}{ Débitos judiciais } & \multicolumn{1}{c|}{$\mathbf{2 0 0 7}$} & $\mathbf{2 0 0 8}$ & $\mathbf{2 0 0 9}$ & \multicolumn{1}{c}{$\mathbf{2 0 1 0}$} \\
\hline Municípios inadimplentes & 584 & 554 & 734 & 781 \\
Total de municípios na base & & 5295 & 5050 & 5438 & 5212 \\
\% inadimplentes & $11 \%$ & $11 \%$ & $13 \%$ & $15 \%$ \\
Estoque da dívida (mil R\$) & 11.134 .523 & 13.937 .800 & 17.625 .375 & 20.788 .459 \\
Pagamentos (mil R\$) & 1.536 .860 & 1.792 .933 & 1.620 .000 & 1.877 .513 \\
\hline
\end{tabular}

FONTE: Elaboração própria, com dados da Secretaria do Tesouro Nacional (Disponível em: <http://www.tesouro.fazenda.gov.br/estados_municipios/index.asp>. Acesso em: 2/8/2011.).

Conforme se verifica na Tabela 2, abaixo, dentre os grandes devedores de precatórios, no ano de 2009, destaca-se o município de São Paulo, que possuía naquele ano uma dívida de 12 bilhões de reais. Entre os demais grandes devedores municipais encontram-se, em sua maioria, municípios do estado de São Paulo, bem como algumas capitais dos outros estados brasileiros.

TABELA 2 - MUNICÍPIOS DO BRASIL: MAIORES ESTOQUES DE PRECATÓRIOS (2009, VALORES CORRENTES)

\begin{tabular}{l|l|r|r|r}
\hline Ordem & \multicolumn{1}{c|}{ Município } & $\begin{array}{c}\text { Estoque } \\
(\mathbf{m i l} \text { R\$) }\end{array}$ & $\begin{array}{r}\text { Despesa total paga } \\
\text { (mil R\$) }\end{array}$ & $\begin{array}{r}\text { \% Estoque/Despesa } \\
\text { total paga }\end{array}$ \\
\hline 1 & São Paulo - SP & 12.276 .048 & 23.263 .718 & $53 \%$ \\
2 & Guarulhos - SP & 743.440 & 1.505 .935 & $49 \%$ \\
3 & Santo André - SP & 648.502 & 1.110 .268 & $58 \%$ \\
4 & Osasco - SP & 484.109 & 999.573 & $48 \%$ \\
5 & Salvador - BA & 346.295 & 2.593 .770 & $13 \%$ \\
6 & Belo Horizonte - MG & 219.785 & 4.399 .553 & $5 \%$ \\
7 & Diadema - SP & 199.128 & 503.149 & $40 \%$ \\
8 & Guarujá - SP & 192.972 & 554.299 & $35 \%$ \\
9 & Campinas - SP & 170.267 & 1.967 .298 & $9 \%$ \\
10 & Cubatão - SP & 118.724 & 458.819 & $26 \%$ \\
11 & Curitiba - PR & 105.242 & 3.791 .556 & $3 \%$ \\
12 & Cuiabá - MT & 103.719 & 717.509 & $14 \%$ \\
13 & Vila Velha - ES & 94.343 & 399.583 & $24 \%$ \\
14 & Rio de Janeiro - RJ & 82.092 & 9.512 .831 & $1 \%$ \\
\hline
\end{tabular}

FONTE: Elaboração própria, com dados da Secretaria do Tesouro Nacional (Disponível em: < http://www.tesouro.fazenda.gov.br/estados_municipios/index.asp>. Acesso em: 2/8/2011.).

Conforme o Relatório Anual de Fiscalização do TCM-SP (TCM-SP, 2010), no ano de 2009, do total de precatórios devidos pelo município de São Paulo, 5,93 bilhões eram precatórios de natureza alimentar, principalmente decorrentes de ações judiciais promovidas por servidores municipais. Já os precatórios não alimentares totalizavam 5,96 bilhões e se referiam a débitos relativos ao parcelamento para pagamento em dez anos, desapropriações do único imóvel residencial do credor e valores complementares do parcelamento originalmente estabelecido na Constituição Federal. As requisições de pequeno valor totalizavam, em 2009, R\$ 953 milhões.

Pouco mais da metade dos estados encontra-se inadimplente e, para a maior parte deles, apresenta-se uma tendência de aumento da dívida, mesmo após o advento da EC 62/2009. 
O certo é que ainda é cedo para serem avaliados os efeitos da referida Emenda Constitucional mas é perceptível que, ao menos no primeiro ano de sua vigência, não houve sensível alteração nas tendências que se apresentavam em anos anteriores.

Os estados que já vinham reduzindo a dívida antes da Emenda, continuaram a reduzíla e aqueles com a dívida crescente mantiveram esta tendência em 2010. Exceção é o estado do Espírito Santo, que não apresenta estoque de dívida de precatórios em 2010 mas isto se deve, provavelmente, a uma deficiência de informação da base do Tesouro Nacional, pois aquele ente estatal não teria como quitar sua dívida de precatórios de 635 milhões de reais com o pagamento de apenas 11 milhões de reais, em $2010^{4}$. A mesma observação pode ser feita em relação aos estados do Rio de Janeiro e de Santa Catarina.

Sobre os dois maiores estados inadimplentes conforme os dados apresentados na Tabela 3 abaixo, São Paulo e Paraná, cabem algumas observações.

TABELA 3 - DÉBITOS JUDICIAIS DOS ESTADOS (VALORES CORRENTES)

\begin{tabular}{|c|c|c|c|c|c|c|}
\hline \multirow{2}{*}{ Estado } & \multicolumn{3}{|c|}{ Estoque (mil R\$) } & \multicolumn{3}{|c|}{ Pagamentos (mil R\$) } \\
\hline & 2008 & 2009 & 2010 & 2008 & 2009 & 2010 \\
\hline Acre & $52.315,64$ & $50.514,10$ & $53.811,21$ & $12.696,72$ & $15.256,21$ & $13.085,62$ \\
\hline Alagoas & - & - & - & $19.519,26$ & $33.409,97$ & $27.166,73$ \\
\hline Amazonas & - & - & - & $11.065,69$ & $17.906,03$ & $14.998,00$ \\
\hline Amapá & - & - & - & $10.983,83$ & $7.901,57$ & $6.246,16$ \\
\hline Bahia & $833.981,24$ & $832.461,51$ & $1.119 .777,47$ & $181.034,98$ & $140.855,28$ & $125.743,48$ \\
\hline Ceará & - & - & - & $47.910,63$ & $31.766,95$ & $32.527,59$ \\
\hline Distrito Federal & - & - & - & $5.425,64$ & 351,78 & 276,60 \\
\hline Espírito Santo & $654.741,46$ & $635.013,07$ & - & $10.981,28$ & $39.368,26$ & $11.061,11$ \\
\hline Goiás & - & - & - & $18.917,64$ & $21.160,14$ & $12.734,01$ \\
\hline Maranhão & - & - & - & $75.048,68$ & $114.701,71$ & $50.129,18$ \\
\hline Minas Gerais & $1.423 .957,27$ & $26.180,49$ & $20.643,55$ & $500.331,94$ & - & $82.457,91$ \\
\hline Mato Grosso do Sul & - & - & - & $29.074,19$ & $74.947,47$ & $104.670,73$ \\
\hline Mato Grosso & - & - & - & $69.642,43$ & $242.011,14$ & $93.551,05$ \\
\hline Pará & - & $14.377,08$ & $23.782,55$ & $52.663,37$ & $23.992,95$ & $26.749,50$ \\
\hline Paraíba & - & - & - & $20.683,78$ & $19.509,05$ & $19.741,26$ \\
\hline Pernambuco & $11.729,30$ & $11.644,78$ & $77.202,82$ & $47.087,58$ & $90.510,50$ & $120.801,36$ \\
\hline Piauí & $325.373,50$ & $342.296,02$ & $346.548,59$ & $46.346,23$ & $50.862,11$ & $64.573,72$ \\
\hline Paraná & 4.109.218,54 & $4.391 .379,50$ & $4.568 .014,69$ & $164.987,94$ & $170.337,05$ & $61.813,03$ \\
\hline Rio de Janeiro & $2.780 .339,59$ & $3.295 .793,82$ & $573.763,37$ & $587.868,84$ & $171.618,94$ & $223.093,62$ \\
\hline Rio Grande do Norte & 349,97 & $2.325,64$ & $2.114,87$ & $53.460,73$ & $38.443,20$ & $37.340,78$ \\
\hline Rondônia & - & - & - & $74.422,02$ & $93.378,42$ & $95.210,52$ \\
\hline Roraima & - & - & - & $11.886,88$ & - & 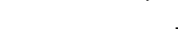 \\
\hline Rio Grande do Sul & $2.056 .087,25$ & $2.297 .127,70$ & $3.182 .325,35$ & $342.718,07$ & $158.052,93$ & $566.433,71$ \\
\hline Santa Catarina & $410.891,57$ & $562.521,17$ & $42.398,23$ & $69.512,49$ & $62.855,69$ & $110.584,51$ \\
\hline Sergipe & $132.913,89$ & $213.332,06$ & 291.669,15 & $32.020,42$ & $28.805,72$ & $13.168,57$ \\
\hline São Paulo & $17.600 .471,40$ & $19.198 .830,44$ & $20.344 .759,08$ & $2.160 .042,90$ & $1.710 .867,48$ & $621.426,25$ \\
\hline Tocantins & $18.888,13$ & $34.876,64$ & $47.883,48$ & $8.226,32$ & $36.142,09$ & $30.935,64$ \\
\hline Brasil & $30.411 .258,75$ & 31.908.674,02 & $30.694 .694,41$ & 4.664.560,48 & $3.395 .012,61$ & $2.566 .520,80$ \\
\hline
\end{tabular}

FONTE: Elaboração própria, com dados da Secretaria do Tesouro Nacional (Disponível em: <http://www.tesouro.fazenda.gov.br/estados_municipios/index.asp>. Acesso em: 2/8/2011).

4 Segundo o levantamento de informações efetuado pelo ministro Ayres Britto por ocasião do julgamento da ADI 4357, o estado do Espírito Santo possui uma dívida judicial de R \$ 9,54 bilhões, aproximadamente. 
De acordo com o TCE-SP, o estado de São Paulo repassou ao Tribunal de Justiça do Estado de São Paulo R\$1,38 bilhões, em cumprimento à EC 62/2009. Deste valor, apenas $\mathrm{R} \$ 16,13$ milhões foram utilizados para pagamentos de precatórios devido, em grande medida, a desencontros entre os cadastros do TJ-SP e da PGE-SP e a atrasos no desenvolvimento de um sistema informatizado (TCE-SP, 2010).

Com relação ao estado do Paraná, deve-se destacar que houve uma diminuição importante nos valores de pagamentos de precatórios que vinham sendo feitos antes da EC 62/2009. De acordo com o TCE-PR, esta diminuição se deveu ao fato de que não está sendo utilizada a totalidade dos valores retidos da Receita Corrente Líquida para a quitação dos débitos, estando a diferença aplicada na conta especial administrada pelo TJ-PR. Também não foi feita ainda a atualização do estoque da dívida para contemplar os juros de mora dos precatórios (TCE-PR, 2009, p. 9).

Desta forma, o montante da dívida de precatórios paranaense continua desconhecido. A fonte de tantas ações judiciais contra os entes da Administração no estado do Paraná ${ }^{5}$ se refere a ações do funcionalismo contra o estado, ações trabalhistas de trabalhadores de empresas terceirizadas e, principalmente, ações de desapropriação do Governo Estadual.

\section{CONSIDERAÇÕES FINAIS}

Em alguns entes federados, a dívida acumulada em precatórios se tornou tão grande que qualquer tentativa de solução certamente se coloca como um compromisso entre os credores da Fazenda Pública e o cidadão que necessita da prestação de serviços do Estado. O orçamento público é finito e não comportaria o pagamento de toda a dívida de precatórios de uma só vez. Este é, inclusive, um entendimento corroborado pelo STF que, em julgamento de pedido de Intervenção Federal 2915 contra o estado de São Paulo, justamente em face de não pagamento de precatórios, pronunciou-se acerca do não cabimento daquela medida com base no Princípio da Reserva do Financeiramente Possível ${ }^{6}$ (MENDES, 2008, p. 1367).

Dos dados apresentados pode-se verificar que o problema da inadimplência de alguns municípios e de mais da metade dos estados brasileiros é importante e constitui hoje um dos grandes obstáculos para o saneamento das contas públicas. Todavia, duas observações são ne-

5 Informação da Procuradoria Geral do Estado do Paraná.

6 Trata-se de uma doutrina com origem em decisão da Corte Constitucional alemã referente a vagas para a educação na qual se afastou a obrigatoriedade de disponibilização de vaga ao ensino superior. Segundo Mânica (2007), a teoria da reserva do possível alemã se refere, na verdade, à aplicação do princípio da razoabilidade. De acordo com o autor, ao ser transplantada para o Brasil, a teoria se transformou em reserva do financeiramente possível, com a qual buscou-se introduzir limites absolutos à efetivação dos direitos fundamentais, com base em restrições de ordem orçamentária. 
cessárias.

Por um lado, qualquer tentativa de solução pressupõe que o problema seja devidamente conhecido e analisado e, assim, destaca-se a necessidade premente de que sejam produzidos dados mais precisos sobre a situação financeira dos entes públicos devedores em face de suas dívidas de precatórios.

Por outro lado, mesmo com as informações parciais que se logrou obter, é patente que há uma grande disparidade de situações entre os entes devedores. A conclusão lógica desta observação é de que qualquer tentativa de equacionamento do problema da inadimplência, embora deva necessariamente partir de um nível geral de abstração e de isonomia no tratamento dos devedores, tem de abrir espaço para a consideração das particularidades de cada um, sob pena de causar graves prejuízos à população.

Embora seja um mecanismo inteligente, desenvolvido ao longo de muitos anos, o instituto dos precatórios tem grande potencial para se prestar a irregularidades pois é complexo e envolve a participação dos Três Poderes para ser devidamente operacionalizado e fiscalizado. Como os precatórios são requisitados por cada tribunal, de forma independente, somente a entidade pública devedora tem toda a informação sobre os seus credores e valores devidos. Com o descumprimento dos pagamentos, as verbas reservadas em orçamentos de anos anteriores, por conta do fenômeno inflacionário, vão perdendo a relação com o valor da condenação (e com o dano a ser reparado). A dívida real somente será conhecida quando forem atualizados os valores devidos para o efetivo pagamento. Agravam esta situação o histórico brasileiro, anterior ao Plano Real, de inflação muito elevada, que fez crescer explosivamente dívidas com grande incidência de correção monetária e a falta de cultura de transparência nas finanças públicas e de seu controle pela sociedade. Também, o mercado de precatórios que se formou por conta do inadimplemento de vários entes federados comportou desvios derivados da incerteza em relação à data do seu recebimento e à própria existência do crédito, bem como sobre o valor real do crédito.

Cumpre destacar algumas questões que podem jogar luz sobre o problema da inadimplência.

Primeiramente, é preciso reconhecer que, pelos números apresentados até o momento, não é possível descartar a instigante tese de Moreira (2010) de que a problemática que envolve a inadimplência dos precatórios é fruto da escassez dos recursos públicos e resultado da estabilização da economia, do controle das receitas e despesas fiscais e do incremento dos direitos fundamentais.

Ainda, há quem defenda que o desequilíbrio do pacto federativo seja uma faceta im- 
portante para a atual configuração do problema aqui discutido. Para os defensores desta tese, um indício a favor deste argumento estaria no fato de que a maior parte dos estados, e alguns municípios, estão inadimplentes, enquanto a União mantém seus pagamentos em dia. O federalismo fiscal significa a partilha dos tributos e das receitas não tributárias entre os entes da federação de forma que os mesmos possam fazer frente ao atendimento dos seus fins (OLIVEIRA, 2008, p. 40). Entretanto, para este autor, "No Brasil, hoje, o pacto fiscal está torto. Há manifesto desequilíbrio em favor da União" (OLIVEIRA, 2008, p. 40)7.

Sob outra perspectiva, é possível sustentar, como fez o ministro Ayres Britto no julgamento da ação direta de inconstitucionalidade em face da EC 62 (em andamento), que a dívida de alguns dos entes inadimplentes somente cresceu devido à simples, e deliberada, falta de pagamento. Dessa forma, o apregoado cenário de colapso financeiro do Estado não parece verdadeiro, ao menos na extensão propalada.

Por fim, Falcão (2008) afirma que, na verdade, os precatórios "nada mais são que um financiamento obrigatório com dinheiro de propriedade do vencedor da lide". Segundo esse autor, trata-se de um financiamento sem prazo certo pois os governos não cumprem a lei, tornando-se inadimplentes, e o que se tem como resultado é a distorção das contas públicas.

A conclusão do presente texto é de que este é um tema que merece receber a atenção, tanto da sociedade quanto da academia, pela complexidade que lhe é inerente e pelo potencial para afetar as contas públicas e, por consequência, a vida de todos os cidadãos que são, necessariamente, credores ou devedores de precatórios, ou ambos.

\section{REFERÊNCIAS}

FALCÃO, J. Uma reforma muito além do Judiciário. Revista Interesse Nacional, São Paulo, ano 1, ed. 1, abr./jun. 2008. Disponível em: < http://interessenacional.uol.com.br/artigos-integra.asp?cd_artigo $=15>$. Acesso em: 14/3/2011.

MÂNICA, F. B. Teoria da reserva do possível: direitos fundamentais a prestações e a intervenção do Poder Judiciário na implementação de políticas públicas. Revista Brasileira de Direito Público, Belo Horizonte, ano 5, n. 18, p. 169-186, jul./set. 2007.

MENDES, G. F. Curso de direito constitucional. 2. ed. São Paulo: Saraiva, 2008.

MOREIRA, E. B. Precatórios e o princípio da reserva do possível. In: SEMINÁRIO SOBRE A EMENDA CONSTITUCIONAL, 62., 2010, Curitiba. Anais... Curitiba: Escola da Magistratura do Paraná, 2010. Disponível em: <http://www.amapar.com.br/emapcom/index. php?conteudo $=$ interno\&codigo $=852 \&$ nucleo $=1>$. Acesso em: 25/8/2010.

OLIVEIRA, R. F. Curso de direito financeiro. 2. ed. São Paulo: Revista dos Tribunais, 2008.

7 Embora não seja um objetivo do presente trabalho discutir a fundo as diversas questões que envolvem o pacto federativo, trata-se de um ponto que toca o tema dos precatórios, sendo importante um aprofundamento nesta análise. 
SARTORI, I. Experiências do Tribunal de Justiça do Estado de São Paulo. In: SEMINÁRIO SOBRE A EMENDA CONSTITUCIONAL, 62., 2010. Curitiba. Anais... Curitiba: EEscola da Magistratura do Paraná. Disponível em: <http://www.amapar.com.br/emapcom/index. php?conteudo $=$ interno\&codigo $=852 \&$ nucleo $=1>$. Acesso em: $25 / 8 / 2010$.

TRIBUNAL DE CONTAS DO ESTADO DO PARANÁ (TCE-PR). Relatório e parecer prévio - Contas do Governador. Caderno de Precatórios. Exercício 2009. Curitiba, 2009. Disponível em: <http://www.tce.pr.gov.br/contasdogoverno2009/>. Acesso em: 1/7/2011.

TRIBUNAL DE CONTAS DO ESTADO DO PARANÁ (TCE-PR). Relatório e parecer prévio - Contas do Governador. Caderno de Precatórios. Exercício 2010. Curitiba, 2010. Disponível em: <http://www.tce.pr.gov.br/contasdogoverno2010/>. Acesso em: 10/9/2011.

TRIBUNAL DE CONTAS DO MUNICÍPIO DE SÃO PAULO (TCM-SP). Relatório anual de fiscalização. Prefeitura do Município de São Paulo. Exercício 2010. São Paulo, 2011. Disponível em: < http://www.tcm.sp.gov.br/relatorios/AnualFiscalizacao/RelatorioAnualDeFiscalizacao2010.pdf>. Acesso em: 11/9/2011. 
